\title{
EFEKTIFITAS YOGA TERHADAP TINGKAT KECEMASAN IBU BERSALIN: STUDI LITERATUR
}

\section{Zuhrotunida}

Fakultas Ilmu Kesehatan, Universitas Muhammadiyah Tangerang, zuhrotunida@gmail.com

\section{INFORMASI ARTIKEL:}

Riwayat Artikel:

Tanggal di Publikasi: Desember 2020

Kata kunci:

Yoga

Kehamilan

Stress

Cemas

$\mathrm{CRH}$

\section{A B S T R A K}

Yoga adalah jenis olahraga tubuh dengan lima teknik inti; penguasaan tubuh (asana), teknik penguasaan napas (pranayama), teknik penguncian energi (bandha), teknik pengendalian energi (mudra), serta teknik pembersihan tubuh (kriya). Dengan latihan Meditasi yang berfokus pada pernafasan yang dilakukan selama yoga, ibu akan terbiasa melakukan nafas pendek dan cepat dengan ritme yang teratur serta panjang dan dalam, baik saat menghirup maupun melepaskan udara. Pelatihan nafas bisa menenangkan calon ibu untuk melalui rasa sakit dalam proses persalinan, serta memicu sistem saraf yang memperlancar pembukaan dan peregangan dinding vagina. Gerakan focus pada masuk dan keluarnya nafas, tekanan oksigen dalam darah akan meningkat dan mengalir ke seluruh tubuh, memperlancar peredaran darah dan memperlancar pemberian nutrisi pada sel sel termasuk pada kelenjar utama Hypothalamus yang mensekresi hormone Cortikorophin realizing hormone $(\mathrm{CRH})$ yang berkaitan dengan pengeluaran Beta-Endorphin (Beta-EP) dan kortisol yang berperan dalam meredam perubahan emosi, cemas dan mood. 


\section{PENDAHULUAN}

Kecemasan merupakan kondisi psikologis yang menunjukan kekhawatiran terkait perasaan yang tidak menentu dan bersifat subjektif. Kondisi cemas dialami oleh banyak orang dan akan lebih meningkat terjadi pada ibu dalam kondisi hamil dan dalam masa menjelang dan saat bersalin. Sepanjang kehamilannya ibu hamil harus melalui berbagai tingkat ketidaknyamanan baik fisik maupun psikologis yang mempengaruhi psikososialnya. Perubahan postur tubuh serta perubahan fisiologis lainnya menimbulkan adanya perasaan ambilvalen, perubahan suasana hati, gangguan emosional dan gangguan kecemasan (Bjelica, 2018).

Kecemasan dalam kehamilan memiliki dampak negative terhadap masa selanjutnya, yakni persalinan, nifas dan pada bayinya (Rwakarema, 2015; Hanifah, 2019). Penelitian lain menyebutkan bahwa kecemasan antenatal dapat menyebabkan komplikasi kehamilan dan persalinan, serta terjadinya penyulit pada bayi baru lahir (kelahiran prematur, BBLR, kematian bayi, asfiksia.(Rondó., 2004; Alder, 2011; Dunkel Schetter and Tanner, 2012; Hanifah, 2019). Tingginya tingkat kecemasan yang dialami oleh para ibu hamil berdasarkan penelitian Aswitami, 2017 adalah 45.7\% ibu mengalami kecemasan yang berat, $25.7 \%$ kecemasan sedang, 22,8\% kecemasan ringan dan $5.8 \%$ tidak mengalami cemas.

Cara yang efektif dalam menanggulangi masalah kecemasan adalah dengan melakukan latihan fisik, seperti meditasi/yoga. Yoga menciptakan keseimbangan antara emosional, mental, fisik dan dimensi spiritual. Yoga merupakan suatu sistem yang komprehensif antara fisik (asana), latihan pernafasan (pranayama), konsentrasi dan meditasi (dharana dan dhyana) dan kontemplatif praktek. Senam yoga pada tahap prenatal ibu hamil membantu fokus ibu hamil terhadap pengaturan ritme nafas, yang tetap berfokus pada perasaan nyaman, aman dan tenang yang dirasakan ibu hamil dalam berlatih. Dengan latihan pernafasan yang dilakukan selama yoga, ibu akan terbiasa melakukan nafas pendek dan cepat dengan ritme yang teratur serta panjang dan dalam baik saat menghirup maupun melepaskan udara. Pelatihan nafas bisa menenangkan calon ibu untuk melalui rasa sakit dalam proses persalinan, serta memicu sistem saraf yang memperlancar pembukaan dan peregangan dinding vagina.

Bentuk meditasi yang dilakukan selama senam ini yaitu berupa imaginasi terbimbing dan mengikuti imaginasi yang diarahkan oleh petugas, selain itujuga latihan Yoga pada ibu hamil bertujuan melatih otot panggul dan sekitarnya, agar menjadi lebih kuat dan elastis. Sirkulasi darah disekitar daerah panggul menjadi lebih lancar sehingga memudahkan ibu melakukan persalinan secara normal (Aswitami, 2017). Hasil penelitian dari Apriliani, 2015 mengemukakan bahwa cara berpikir positif yang dibangun oleh ibu hamil terkait persalinan adalah salah satu bentuk manfaat yang didapatkan dari senam yoga pada tahap relaksasi yang dalam. Penelitian sebelumnya yaitu Battledi, 2015 Amerika Serikat, Bershadsky, 2014 di California Selatan, dan Kinser di Virginia menemukan bahwa intervensi senam prenatal yoga pada wanita hamil efektif dalam mengurangi kecemasan pada ibu hamil. Berdasarkan hasil penelitian Ashari, 
2019; Aswitami, 2017 didapatkan perubahan signifikan tingkat kecemasan pada ibu hamil setelah melakukan latihan yoga.

\section{METODE PENELITIAN}

Strategi pencarian Penelitian ini merupakan studi literature yang mencari database dari berbagai referensi, seperti jurnal penelitian, review jurnal, annual report, buku dan data - data yang berkaitan dengan Yoga, Kecemasan, Kehamilan dan Persalinan yang diterbitkan pada tahun 2009 - 2019. Pencarian literature dilakukan dengan menggunakan mesin pencari google di internet dengan kata kunci : Yoga, Kecemasan, Stress, Kehamilan dan Persalinan. Database yang diambil dari artikel yang dipublikasikan pada Googleschooler, PubMed dan Researchgate.

\section{Kriteria seleksi data}

Bahan yang dicari diseleksi dengan menggunakan kriteria inklusi. Kriteria inklusi yang digunakan adalah EfektefitasYoga dengan Kecemasan pada ibu bersalin. Sumber yang digunakan hanya terfokus pada Yoga dengan Kecemasan pada ibu bersalin

Sedangkan untuk kriteria eksklusi yaitu jurnal - jurnal yang diterbitkan dibawah tahun 2009.

\section{HASIL DAN PEMBAHASAN}

Dari studi literatur didapatkan hasil sebagai berikut :

\section{Tabel 1. Hasil Studi Literatur}

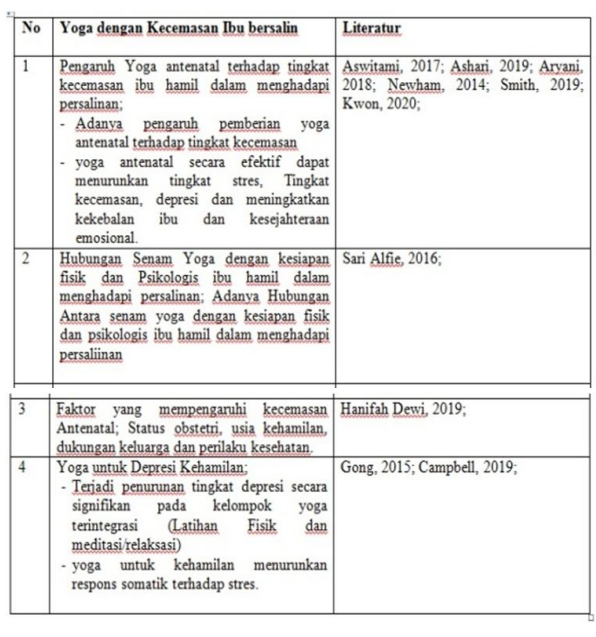

\section{Yoga dan Tingkat Kecemasan Ibu} Bersalin

Yoga adalah jenis olahraga tubuh, pikiran dan mental yang sangat membantu ibu hamil melenturkan persendian, termasuk menenangkan pikiran. Seni yang telah lama berkembang sejak ribuan tahun yang berasal dari India ini, sebagai suatu bentuk penghargaan terhadap janin dan proses terjadinya kehamilan. Senam yoga merupakan program olahraga ringan dimana latihannya menggabungkan prinsip-prinsip yoga.

Latihan yoga yang dilakukan diantaranya mencakup berbagai relaksasi, mengatur postur, olah napas dan meditasi selama satu jam setiap hari. Gerakan relaksasi, mengatur postur dan olah nafas ini sama dengan gerakan yang dilakukan pada saat senam hamil, karena teknik gerakannya menitikberatkan kepada latihan otototot. Bentuk meditasi yang dilakukan selama senam ini yaitu berupa imaginasi terbimbing, membuat calon ibu lebih 
releks. Gerakan prenatal yoga dirancang khusus untuk melatih otot-otot rahim dan otot panggul agar menjadi lebih kuat dan elastis. Sirkulasi darah disekitar daerah panggul menjadi lebih lancar sehingga memudahkan ibu melakukan persalinan secara normal. Dengan latihan pernafasan yang dilakukan selama yoga, ibu akan terbiasa melakukan nafas pendek dan cepat dengan ritme yang teratur serta panjang dan dalam baik saat menghirup maupun melepaskan udara. Pelatihan nafas bisa menenangkan calon ibu untuk melalui rasa sakit dalam proses persalinan, serta memicu sistem saraf yang memperlancar pembukaan dan peregangan dinding vagina.

Gangguan cemas merupakan salah satu gangguan psikiatri yang paling sering dijumpai. Menurut laporan The National Comorbidity Study, satu dari empat orang memenuhi kriteria diagnosis untuk setidaknya satu gangguan kecemasan. Gangguan cemas juga lebih banyak terjadi pada wanita $(30,5 \%)$ daripada pria $(19,2 \%)$. (Sadock, 2015).

Kecemasan menjelang persalinan yang dikarenakan takut pada proses persalinan sangat berpengaruh pada fungsi tubuh ibu saat bersalin. Kecemasan menyebabkan vasokontriksi sehingga aliran darah terhambat dan berkurang. Vasokontriksi akan mempengaruhi organ-organ yang terlibat pada proses persalinan menjadi tidak dapat berfungsi dengan baik. Tenaga mengedan menjadi kurang kuat, dorongan dari dalam tubuh pun tidak kuat, sehingga persalinan terhambat (Artanty, 2011). Data WHO (2010) menunjukkan sekitar 5\% wanita tidak hamil mengalami kecemasan, 8-10\% selama kehamilan, dan meningkat menjadi $13 \%$ ketika menjelang persalinan. Studi lain mengungkapkan bahwa terdapat $67 \%$ ibu hamil menyatakan agak cemas menjelang persalinannya, $12 \%$ sangat cemas dan sisanya $23 \%$ menyatakan tidak cemas (Artanty, 2011).

\section{Efektifitas Yoga terhadap tingkat kecemasan ibu bersalin}

Berdasarkan hasil studi literatur yang dilakukan bahwa melakukan senam yoga secara teratur saat masa kehamilan memiliki dampak positif terhadap penurunan tingkat kecemasan ibu saat bersalin, berikut beberapa uraiannya;

Wanita memiliki potensi $11,3 \%$ lebih besar untuk megalami cemas dibandingkan dengan laki-laki. Peristiwa Kehamilan dan persalinan yang menjadi salahsatu kodrat nya wanita, menambah potensi yang besar untuk timbulnya rasa cemas, hal ini dikarenakan semua kehamilan dianggap berisiko, pengalaman hamil dan bersalin setiap individu berbeda-beda dan penuh ketidakpastian. Semakin mendekati proses persalinan, maka perhatian dan fikiran ibu mulai tertuju pada suatu proses yang dianggap menjadi klimaksnya.

Yoga dalam kehamilan, bertujuan untuk melatih dan mempersiapkan ibu secara menyeluruh, bukan hanya secara fisik, namun juga mental dan spiritualnya sebagai manusia. Yoga melatih otot-otot tubuh yang disertai cara olah nafas. Melalui gerakan tubuh yang disertai teknik pengaturan nafas dan pemusatan konsentrasi, fisik akan lebih sehat, bugar, kuat dan emosi akan lebih seimbang. Latihan senam yoga terdiri dari lima teknik inti, yaitu teknik penguasaan tubuh (asana), teknik penguasaan napas (pranayama), teknik penguncian energi (bandha), teknik 
pengendalian energi (mudra), serta teknik pembersihan tubuh (kriya) yang dapat berman faat selama masa kehamilan.

Penurunan kecemasan yang dipengaruhi oleh prenatal yoga ini akibat dari rasanyaman yang dirasakan ibu hamil selama mengikuti kelas, sehingga akan membuat otot-otot rileks, pikiran tenang, dan meningkatkan kemampuan berkonsentrasi. Secara teoritis kecemasan akan turun jika individu mengalami relaksasi pada tubuhnya (Spielberger, 1966). Latihan prenatal yoga adalah sebuah treatmen fisik yang ternyata juga dapat memberikan efek psikologis karena memberikan efek relaksasi pada tubuh seseorang dan mempengaruhi beberapa aspek psikologis padaseseorang yang melakukannya dikatakan dapat membantu menurunkan kecemasan (Aprilia, 2014). Unsur pada prenatal yoga yang dapat membantu menurunkan kecemasan adalah pada bagian relaksasi dan meditasi.Teknik ini diharapkan dapat meringankan keluhan ibu hamil selama kehamilan terutama terkait kram dan edema yang sering pada akhir kehamilan, memperlancar aliran darah serta nutrisi ke janin, membantu posisi bayi dan pergerakannya, meningkatkan energi serta nafsu makan, menciptakan ketenangan dan fokus, mengurangi perasaan mual, meredakan ketegangan di leher rahim, mengurangi ketegangan, cemas dan depresi selama hamil, merenggangkan otot-otot, membuat nyenyak tidur serta membantu mengurangi nyeri pinggang atau punggung bawah akibat peregangan otot-otot sekitar perut. Menurut Jerath et al (2009), pernapasan dalam dapat mengaktifkan sistem saraf parasimpatis, terutama dengan meregangkan jaringan paru dan saraf vegal. Hal ini menyebabkan respon fisiologis ditandai dengan penurunan denyut jantung, tekanan darah, tingkat metabolisme, dan konsumsi oksigen. Pernapasan dalam juga meningkatkan neuroplastisitas, yang didefinisikan sebagai reorganisasi jalur saraf sebagai respon adaptif. Secara umum orang yang melakukan yoga akan mendapatkan banyak manfaat, salah satunya adalah menurunkan kecemasan pada ibu hamil.

Meditasi, atau semadi, adalah praktik relaksasi yang melibatkan pelepasan pikiran dari semua hal yang menarik, membebani, maupun mencemaskan dalam hidup kita seharihari. Meditasi merupakan salah satu aktifitas inti dalam yoga yang bertujuan memberikan kenyamanan dan ketenangan. Inti dari meditasi, yaitu fokus pada masuk dan keluarnya napas. Dengan begitu, pikiran mengenai hal-hal yang membuat stres akan menjauh dengan sendirinya. Pada saat bermeditasi, gerakan focus pada masuk dan keluarnya nafas, tekanan oksigen dalam darah akan meningkat dan mengalir ke seluruh tubuh, memperlancar peredaran darah dan memperlancar pemberian nutrisi pada sel sel termasuk pada kelenjar utama Hypothalamus.

Hypothalamus menghasilkan beberapa hormone yang berkhaitan dengan emosi, stress dan mood yaitu diantaranya adalah hormone oksitosin dan cortikotropin realizing hormone (CRH). CRH berhubungan dengan perubahan mood positif dan berkhaitan dengan pengeluaran kortisol hormone dan Beta endhorphin (beta- EP). Sebagai respon dalam keadaan stres, hipotalamus secara langsung mengaktifkan sistem saraf simpatis. Mengeluarkan $\mathrm{CRH}$ untuk merangsang sekresi ACTH dan kortisol, dan memicu 
pengeluaran vasoprespin yang bertujuan untuk menekan stres.

Tingkat stres maternal yang tinggi dapat menyebabkan peningkatan kadar CRH pada kehamilan. Diketahui bahwa stres kronis selama kehamilan akan mengakibatkan peningkatan dan pelepasan hormon yang berperan dalam persalinan, diantaranya CRH, ACTH, kortisol, esterogen, progesteron, prostaglandin, dan hormon lainnya. Stres kronis akan menstimulasi pengaktivan HPA aksis. (Hacker, 2010; Cunningham et al, 2014; Ganong, 2015).

Mekanisme HPA aksis ditandai dengan adanya stres dan anxietas yang biasanya terjadi pada primipara muda yang mempunyai predisposisi genetik. Aksis HPA ini menyebabkan Stres pada ibu maupun janin yang berdampak pada peningkatan pelepasan hormon Corticotropin Releasing Hormone (CRH), perubahan pada Adrenocorticotropic Hormone (ACTH), prostaglandin, reseptor oksitosin, matrix metaloproteinase

(MMP),

cyclooksigenase-2,

dehydroepiandrosteron sulfate (DHEAS), interleukin-8 estrogen plasenta, progesteron dan pembesaran kelenjar adrenal (Hacker, 2010; Cunningham et al, 2014).

\section{DAFTAR PUSTAKA}

Aswitami, 2017. Pengaruh Yoga Antenatal terihadap tingkat kecemasan pada ibu hamil TW III dalam menghadapi Proses Persalinan Di klinik Yayasan Bumi Sehat. JURNAL KESEHATAN TERPADU 1(1) : 1-5 ISSN : 2549 - 8479

Bjelica, A., Cetkovic, N., TrninicPjevic, A., \& Mladenovic-Segedi, L. (2018). The phenomenon of pregnancy-a psychological view. Ginekologia polska, 89(2), 102-106.

Hanifah, 2019. Faktor factor yang memengaruhi kecemasan Antenatal. JURNAL KEBIDANAN Vol 5, No 1, Januari $2019: 16-23$.

Aprilliani, wahyudi, 2015. Pengaruh yoga prenatal terhadap kecemasan sesaat dalam menghadapi persalinan pada primigravida trimester III. Proceeding Psikologi, ISSN; 2460 - 5448.

Battle, C. L., Uebelacker, L. A., Magee, S. R., Sutton, K. A., Miller, I. W. Potential for Prenatal Yoga to Serve as an Intervention to Treat Depression During Pregnancy. Women's Health Issues : Official Publication of the Jacobs Institute of Women's Health. 2015;25(2):134-141.

Bershadsky, S., Trumpfheller, L., Kimble, H. B., Pipaloff, D., Yim, I. S. The Effect of Prenatal Hatha Yoga on Affect, Cortisol and Depressive Symptoms. Complementary Therapies in Clinical Practice. 2014;20(2):106113.

Ashari, 2019. Pengaruh senam prenatal yoga terhadap penurunan kecemasan ibu hamil trimester III. The Indonesian Journal of public health vol. 15 No. 1. E-ISSN; $2356-4067$.

Newham ${ }^{1}$, Anja Wittkowski,, et al, 2014. Effects of antenatal yoga on maternal anxiety and depression: a randomized controlled trial. 014 Aug;31(8):631-40. Doi; 10. 1002/da. 22268. https://pubmed.ncbi.nlm.nih.gov/ $\underline{24788589 /}$ 
Smith CA, Shewamene Z, Galbally M, Schmied V, Dahlen H.J. The effect of complementary medicines and therapies on maternal anxiety and depression in pregnancy: A systematic review and meta-analysis Affect Disord. 2019 Feb 15;245:428$439 . \quad$ doi: 10.1016/j.jad.2018.11.054. Epub 2018 Nov 6.PMID: 30423471. https://pubmed.ncbi.nlm.nih.gov/

Rachel Kwon ${ }^{1}$, Kelly Kasper $^{2}$, Sue London $^{2}$, David M Haas ${ }^{2}$ A systematic review: The effects of yoga on pregnancy. PMID: 32446148

DOI: $10.1016 /$ j.ejogrb.2020.03.04 $\underline{4}$

Alfie, 2016. Hubungan senam yoga dengan kesiapan fisik dan psikologis ibu hamil dalam menghadapi persalinan di kelas antepartum gentle yoga Yogyakarta. Jurnal Terpadu Ilmu Kesehatan, Volume 5, No 2, November 2016, hlm 110-237.

Gong. Yoga for prenatal depression; a systematic review and metaanalysis. BMC Psychiatry. 2015 Feb 5;15:14. doi: 10.1186/s12888-015-0393-

1.PMID: 25652267

Campbell V, Nolan M. 'It definitely made a difference': A grounded theory study of yoga for pregnancy and women's selfefficacy for labour.Midwifery. 2019 Jan;68:74-83. doi: 10.1016/j.midw.2018.10.005. Epub $2018 \quad$ Oct 17.PMID: 30396001 